\title{
Image Case: Gastric Corpus Angiodysplasias in 61 years old Egyptian Man Presented by Dysphagia
}

\author{
Mohamad Refaey,Tarik Zaher \\ Department of Tropical Medicine, Faculty of Medicine, Zagazig University, Egypt
}

Corresponding Author Tarik Zaher

\section{Mobile:}

+0201001855393

\section{E mail:}

tareqzaher@gmail.com

\section{Key words:}

Gastric;Angiodysplasi as
Upper gastrointestinal endoscopy of 61 years old Egyptian man presented by dysphagia revealed : normal esophageal mucosa without

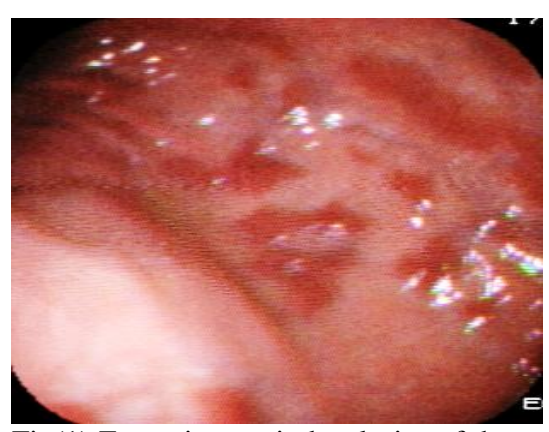

Fig(1):Extensive angiodysplasias of the corpus of the stomach. masses, ulcers nor stricture; just sliding hiatus hernia. On examination of the stomach there were extensive angiodysplasias of the corpus of the stomach as shown in figures (1) and (2).

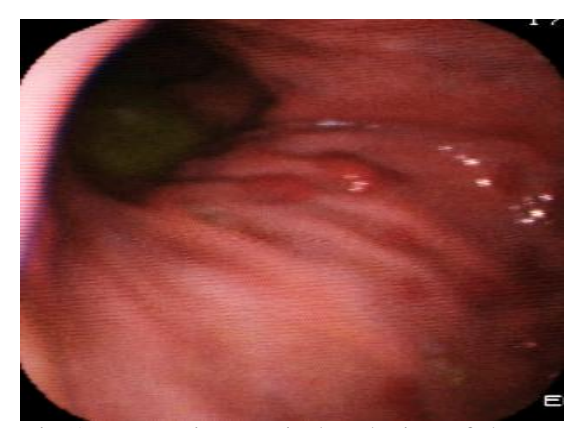

Fig(2):Extensive angiodysplasias of the corpus of the stomach. 